\title{
$\mathrm{CAE}$ 해석을 이용한 자동차용 $\mathrm{AA6061}$ 리어 서브-프레임의 경량화 설계
}

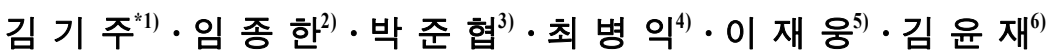

서정대학 자동차과 ${ }^{1)} \cdot$ 가천대학교 기계·자동차공학과 ${ }^{2)}$. 동명대학교 메카트로닉스공학과 ${ }^{3)}$ - 한국기계연구원 나노역학팀 ${ }^{4)}$. 지에스원 연구개발팀 ${ }^{5)} \cdot$ 고려대학교 기계공학과 ${ }^{6}$

\section{Light-weight Design of Automotive AA6061 Rear Sub-frame Based on CAE Simulation}

\author{
Kee Joo $\mathrm{Kim}^{*}{ }^{* 1} \cdot$ Jong Han $\mathrm{Lim}^{2)} \cdot \mathrm{Jun}^{\mathrm{H}} \mathrm{Hyub} \mathrm{Park}^{33} \cdot$ Byung-Ik Choi ${ }^{4)}$ • \\ Jae-Woong Lee ${ }^{5)} \cdot$ Yoon-Jae Kim ${ }^{6}$ \\ ${ }^{1)}$ Departmnet of Automobile Engineering, Seojeong College, Gyeonggi 482-777, Korea \\ ${ }^{2)}$ Department of Mechanical \& Automotive Engineering, Gachon University, Gyeonggi 461-701, Korea \\ ${ }^{3)}$ Department of Mechatronics Engineering, Tongmyong University, Busan 608-711, Korea \\ ${ }^{4)}$ Nano Mechanics Team, Korea Institute of Machinery \& Materials, 1 Jang-dong, Yuseong-gu, Daejon 305-343, Korea \\ ${ }^{5)}$ Research \& Development Team, GS-ONE Company, 48-3 Yeongjang-ri, Gwangtan-myeon, Paju-si, \\ Gyeonggi 413-851, Korea \\ ${ }^{6)}$ Department of Mechanical Engineering, Korea University, Seoul 136-701, Korea \\ (Received 11 June 2011 / Revised 10 August 2011 / Accepted 6 September 2011)
}

\begin{abstract}
It is well known that the targeted fuel efficiency could only be achieved by more than $40 \%$ reduction of the vehicle weight through improved design and extensive utilization of lightweight materials. In order to obtain the goal of the weight reduction of automobiles, the researches about lighter and stronger rear sub-frame have been studied without sacrificing the safety of rear sub-frame. In this study, the weight reduction design process of rear sub-frame could be proposed based on the variation of von-Mises stress contour by substituting an AA6061 (aluminum 6061 alloy) having tensile strength of $310 \mathrm{MPa}$ grade instead of SAPH440 steels. In addition, the stress ratio variations (stress over fatigue limit) of the rear sub-frame were examined and compared carefully. It could be reached that this approach method could be well established and be contributed for light-weight design guide and the optimum design conditions of the automotive rear sub-frame development.
\end{abstract}

Key words : AA6061(알루미늄 6061 합금), Rear sub-frame(리어 서브-프레임), Light weight(경량화), Design(설 계), $\mathrm{CAE}$ (컴퓨터 응용 공학)

\section{1. 서 론}

국내에서는 자동차 배기량에 관계없이 5 개 등급 으로 단일화하여 에너지 소비효율이 $15 \mathrm{~km} / \ell$ 이상 이면 1 등급으로 분류하여 각종 세제혜택이 주어질 예정이다. 또한, 유럽 연합은 교토의정서에 의거하

"Corresponding author, E-mail: kjkim@seojeong.ac.kr
여 2012년까지 온실가스 배출을 1990년 대비 $8 \%$ 감 축 시킬 것을 목표로 2012년 유럽에서 판매되는 자 동차 신차의 이산화탄소 배출량이 $130 \mathrm{~g} / \mathrm{km}$ 을 초과 시, 2012년 20€/g, 2013년 30€/g, 2014년 $60 € / g$, 2015 년 $95 € / \mathrm{g}$ 로 각각 단계적으로 벌과금을 부과할 예정이다.

$$
\text { 이에, 각국의 자동차사는 자동차 배출가스로 인 }
$$


한 이산화탄소의 발생량을 연비향상을 통해 감소시 키기 위하여 자동차 경량화 및 엔진 마찰손실 저감 등의 연료 고효율화 기술개발에 총력을 기울이고 있다. ${ }^{1-4)}$

본 연구에서는 인장강도 $310 \mathrm{MPa}$ 급 $\mathrm{AA} 6061$ 알루 미늄 합금 소재를 이용한 리어 서브-프레임의 경량 화 설계 과정을 기존의 상용화로 검증된 SAPH440 Steel 소재로 제작된 서브-프레임을 참고로 하여 $\mathrm{CAE}$ 를 이용해 다루고자 한다. 특히, von Mises stress 를 피로한도로 정규화(normalizing)하여 안전계수 와 같은 형태의 안전율을 부여하여 피로특성을 정 적해석결과로 단순하게 계산하는 방법을 제시하고 자 한다.

\section{2. 해석 방법}

새시부품의 대물 파트인 리어 서브프레임(Rear Sub-frame)은 자동차 새시 부품으로서 승용차의 뒷 쪽 하단부에 위치하여 액슬(Axle)을 서브할 뿐만 아 니라 차체와 휠(Wheel)을 연결하는 역할을 한다. 뒷 쪽 휠은 이 부품에 여러 개의 링크 부품으로 연결되 는 서스펜션으로 구성하여 편안한 승차감을 제공한 다. 이 리어 서브프레임은 2 개의 사이드 멤버(Side Member)와 앞-뒤 크로스 멤버(Cross Member) 및 1 6번 브라켓으로 구성된다. 본 연구에서는 SAPH440 소재로 개발된 리어 서브-프레임의 구성 파트를 알 루미늄 6061 합금으로 소재변경하여 경량화 설계를 진행하였으며 Fig. 1에 그 형상과 구성부품명을 나 타내었다.

Fig. 2에 모듈형태로 제작된 리어 서브-프레임의

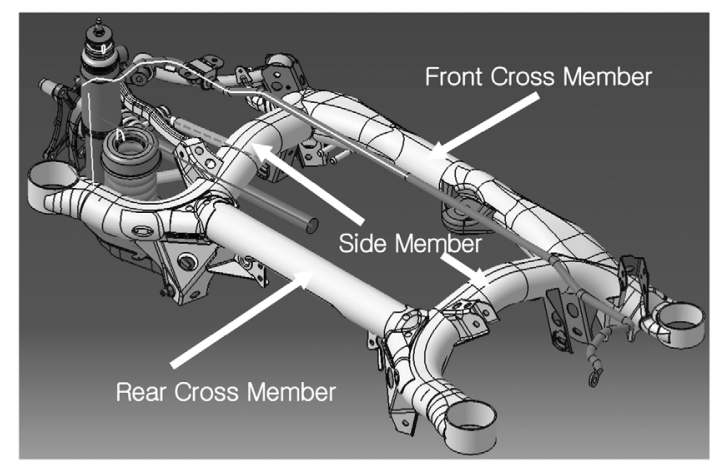

Fig. 1 Geometry of rear sub-frame

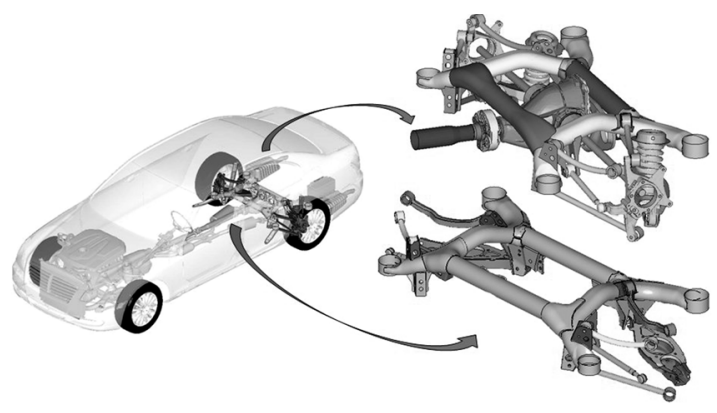

Fig. 2 Rear sub-frame module assembled in vehicle

차량 장착 위치를 나타내어 리어 서브-프레임의 차 량 구조물 상 역할을 상세히 나타내었다.

$\mathrm{CAE}$ 해석은 상용프로그램으로 검증된 Nastran 프로그램을 이용하였으며 Fig. 3에 해석에 사용한 경계조건을 나타내었는데, 리어 서브-프레임이 차 체와 연결되는 가장자리 4 곳을 고정(fixed point) 후 6 개의 브라켓 각각에 $\mathrm{x}, \mathrm{y}, \mathrm{z}$-방향으로 단위 하중을 부여 시 최대 응력값을 구하여 AA6061 재질 및 SAPH440 소재로 제작된 서브-프레임을 비교하였 다(소재물성은 Table 1 참조).

식 (1)은 무게인자(weight function; WF) 개념을 나

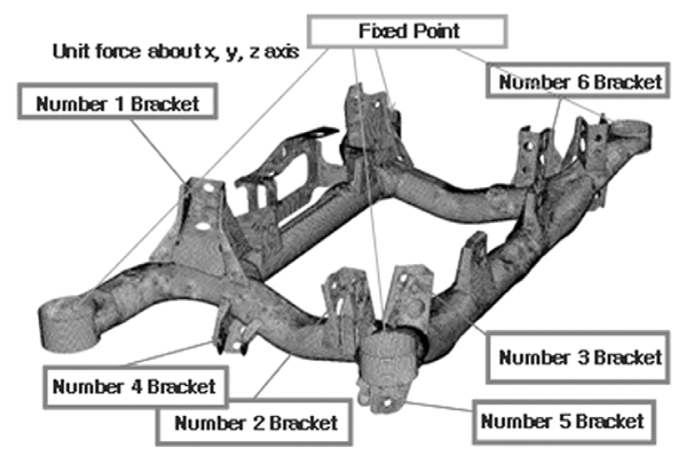

Fig. 3 Element shape and boundary conditions

Table 1 Mechanical properties of AA6061 and SAPH440

\begin{tabular}{|c|c|c|}
\hline & SAPH440 (2.3mm) & AA6061 $(5.0 \mathrm{~mm})$ \\
\hline Young's modulus & $206.8 \mathrm{GPa}$ & $73.0 \mathrm{GPa}$ \\
\hline Poisson's ratio & 0.29 & 0.33 \\
\hline Density & $7.85 \mathrm{~g} / \mathrm{cm}^{3}$ & $2.75 \mathrm{~g} / \mathrm{cm}^{3}$ \\
\hline Yield strength & $305.0 \mathrm{MPa}$ & $276.0 \mathrm{MPa}$ \\
\hline Ultimate strength & $440.0 \mathrm{MPa}$ & $310.0 \mathrm{MPa}$ \\
\hline Fatigue limit & $\begin{array}{c}208.8 \mathrm{MPa} \\
\text { (at } 1 \times 10^{6} \text { cycles) }\end{array}$ & $\begin{array}{c}96.5 \mathrm{MPa} \\
\text { (at } 5 \times 10^{8} \text { cycles) }\end{array}$ \\
\hline
\end{tabular}


타낸 것이고 이를 도입하면 소재의 피로한도에 대 해 부품에 작용하는 응력비(stress ratio)를 구할 수 있다.

$$
W F=\frac{\sigma}{\sigma_{f}}
$$

식 (1)에서 $\sigma$ 는 해석을 통한 각 부위별 von-Mises stress 값을 나타내며 $\sigma_{f}$ 는 피로한도(fatigue limit)를 나타내는 데 본 연구에서 사용한 $2.3 \mathrm{~mm}$ 두께를 갖 는 SAPH440 판재 및 $5.0 \mathrm{~mm}$ 두께의 AA6061 판재의 피로한도는 Table 1 에 나타낸 것과 같이 각각 208.8 $\mathrm{MPa}$ (100만 사이클 기준) 및 $96.5 \mathrm{MPa}$ (5억 사이클 기준)이다.

식 (1)을 이용하여 최적화 설계기준을 정할 수 있 는 데 AA6061에 대한 무게인자는 SAPH440에 대한 무게 인자에 최대한 근접하게 설계하며 이를 넘지 않게 설계하는 것이 필요하다. 예를 들어 단위하중 에 대한 해석결과 SAPH440 및 AA6061의 최대 von-Mises 응력은 각각 $100 \mathrm{MPa}, 50 \mathrm{MPa}$ 의 결과를 계산·예측한 경우 $\mathrm{SAPH} 440$ 의 무게인자 $=\sigma / \sigma_{f}=$ $100 / 208.8=0.479$ 로 계산되며 AA6061 의 무게인자 $=$ $\sigma / \sigma_{f}=50 / 96.5=0.518$ 로 계산된다. 이 때 AA6061의 무게인자 값이 SAPH440 보다 작으므로 AA6061을 보강하여 0.479 에 근접하며 이 값을 넘지 않도록 설 계해야 파괴 없는 안전한 서브-프레임을 설계할 수 있을 것이다.

\section{3. 리어 서브-프레임 해석 결과 및 고찰}

Fig. 4에 리어 서브-프레임의 3번 브라켓 주위 응 력집중부를 나타내었는데 이러한 형태로 여러 부위 의 각 노드(node)를 따라(normalized distance) SAPH440 소재 및 AA6061 합금 소재에 대한 1,2,3, 4, 5 및 6번 브라켓의 X- 방향 단위 하중에 대한 응력비의 변화 해석값을 부위별로 나타낸 것이 Fig. 5(a), (b), (c), (d), (d), (e) 및 (f)이다.

SAPH440 소재 및 AA6061 합금 소재에 대한 3번 브라켓의 X- 방향, Y-방향 및 Z-방향 단위 하중에 대 한 응력비의 변화 해석값을 부위별로 나타낸 것이 각각 Fig. 6(a), (b) 및 (c)이다.

Fig. 5(c)에 나타나듯이 AA6061의 초기 두께 5.0

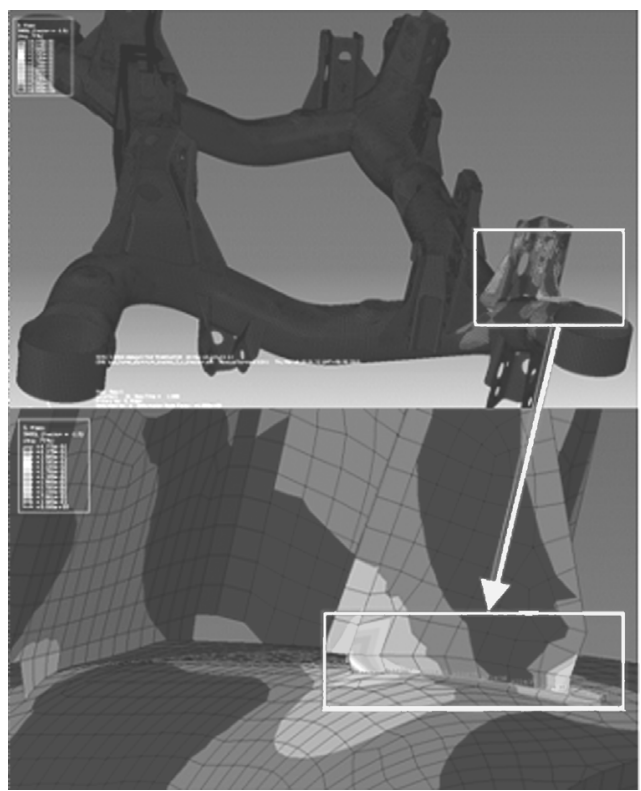

Fig. 4 Contour showing maximum von-Mises stress

$\mathrm{mm}$ 로 해석된 결과가 무게인자로 SAPH440과 비교 할 때 여유가 있으므로 SAPH440의 무게인자와 $\mathrm{AA} 6061$ 의 무게인자가 가장 근접한 모드에서 다양 한 두께해석을 통해 최적화 두께를 찾았으며 그 결 과를 Fig. 7 에 나타내었다. 그 두께를 $4.2 \mathrm{~mm}$ 까지 줄 인 결과 SAPH440과 유사한 형태의 무게인자를 나 타내는 것을 알 수 있었으며 이로부터 AA6061은 $4.2 \mathrm{~mm}$ 가 설계기준을 만족하는 최적화 두께임을 알 수 있다.

Table 2에 SAPH440 및 AA6061으로 리어 서브-프 레임을 제작 시 체적, 밀도 및 무게를 비교하여 나타 내었으며 무게인자를 고려 시 기존의 SAPH 소재보 다 AA6061로 서브-프레임 제작할 때 $36.8 \%$ 의 경량 화가 가능함을 알 수 있었다.

\section{4. 결 론}

본 연구에서는 인장강도 $310 \mathrm{MPa}$ 급 AA6061 알루 미늄 합금 소재를 이용한 리어 서브-프레임의 경량 화 설계 과정을 기존의 상용화로 검증된 SAPH440 Steel 소재로 제작된 서브-프레임을 참고로 하여 $\mathrm{CAE}$ 를 이용해 계산하였다. 특히, von Mises stress를 피로한도로 정규화(normalizing)하여 안전계수와 같 은 형태의 안전율을 부여하여 피로특성을 정적해석 


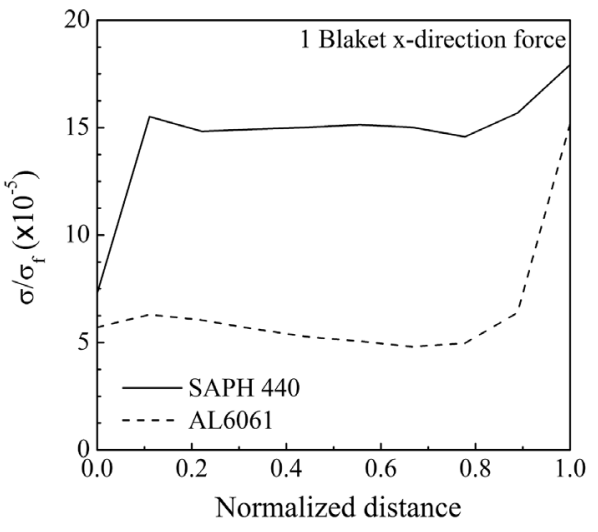

(a) Number 1 bracket (x-direction force)

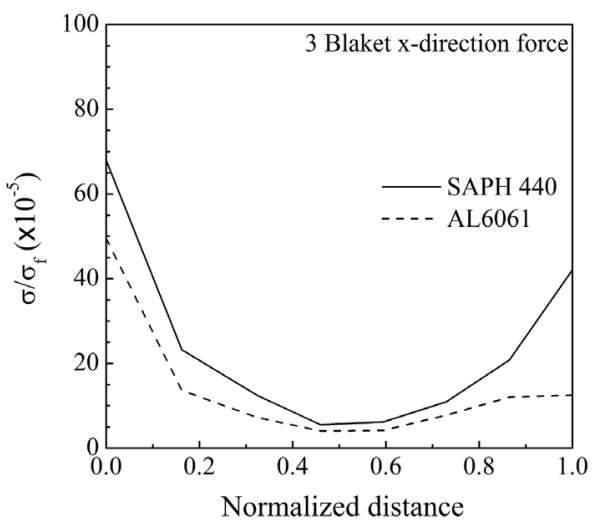

(c) Number 3 bracket (x-direction force)

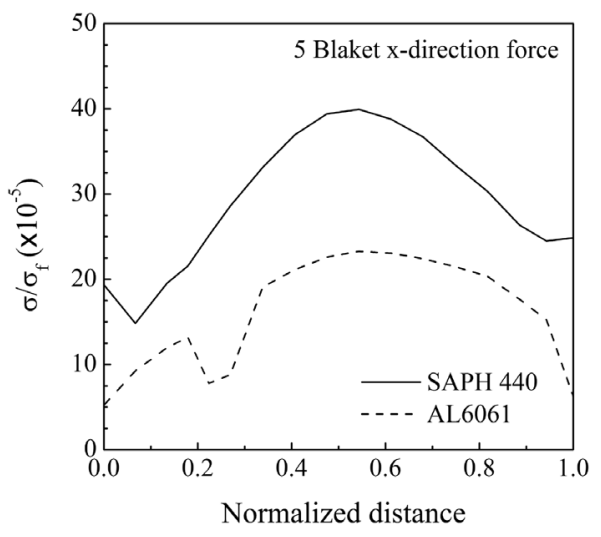

(e) Number 5 bracket (x-direction force)

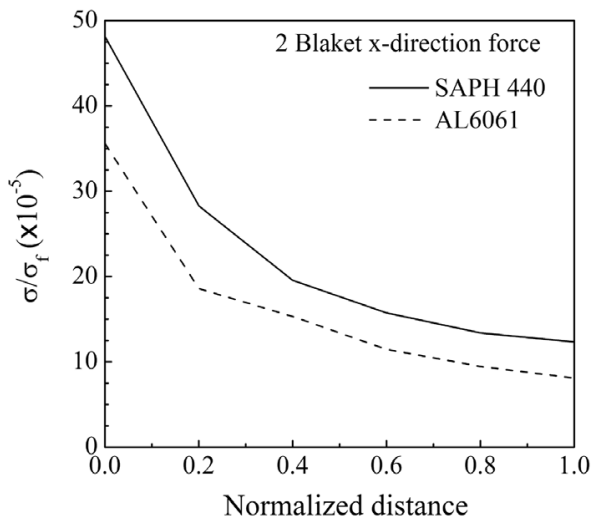

(b) Number 2 bracket (x-direction force)

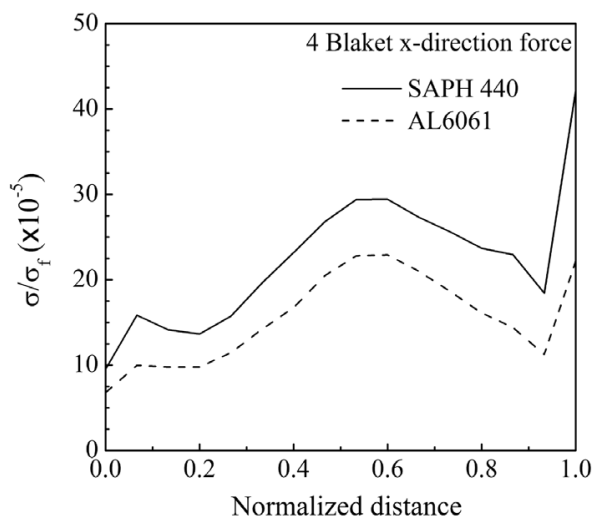

(d) Number 4 bracket (x-direction force)

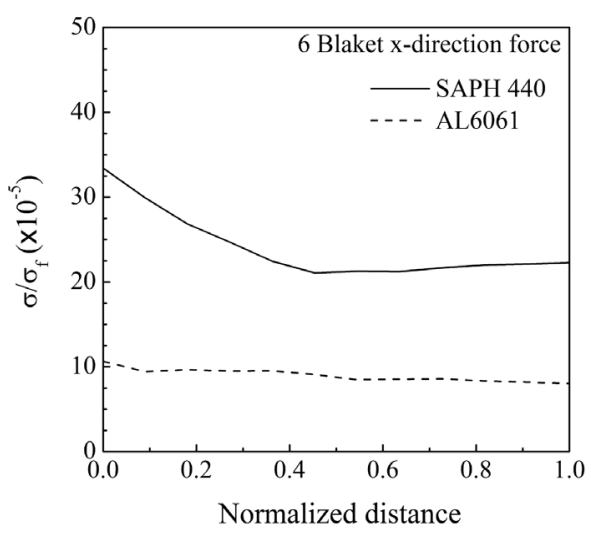

(f) Number 6 bracket (x-direction force)

Fig. 5 Stress ratio comparison between SAPH440 and AA6061 following as normalized distance

결과로 단순하게 계산하는 방법을 제시하고자 한 가장 근접한 모드에서 다양한 두께해석을 통해 최 다. SAPH440의 무게인자와 AA6061의 무게인자가 적화 두께를 찾아내었으며 이를 통해 최대 $36.8 \%$ 의 


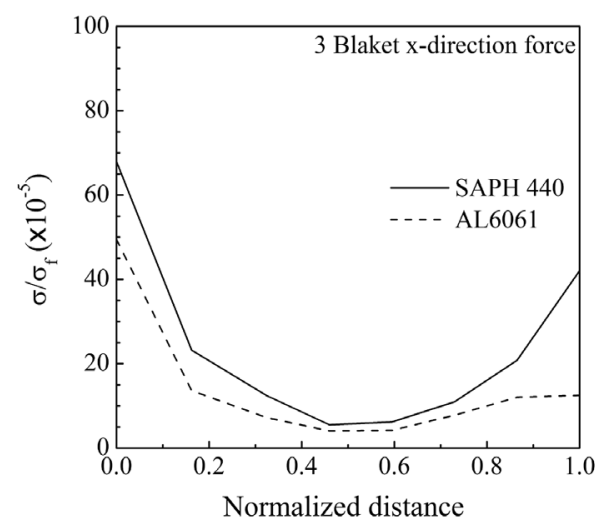

(a) Number 3 bracket (x-direction force)

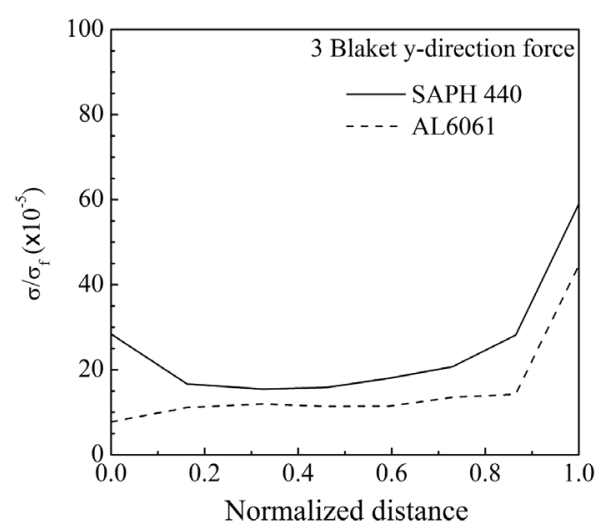

(b) Number 3 bracket (y-direction force)

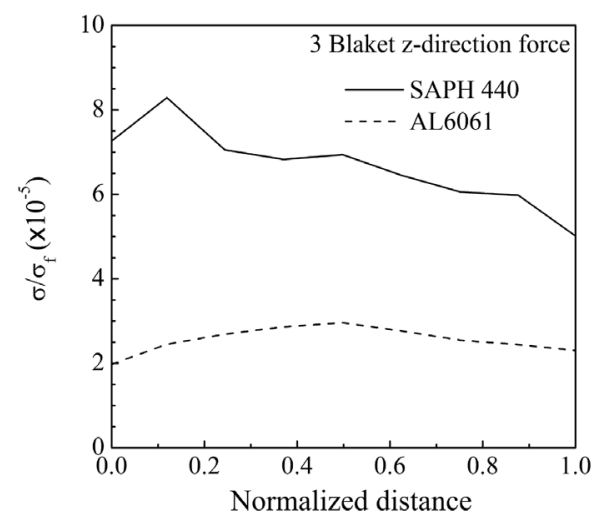

(c) Number 3 bracket (z-direction force)

Fig. 6 Stress ratio comparison between SAPH440 and AA6061 following as normalized distance at bracket 3

경량화가 가능함을 알 수 있었으며 2 배수 안전율을 고려하더라도 $18 \%$ 이상의 경량화 가능성을 알 수 있었다. 본 논문에서 제시하는 무게인자와 응력비

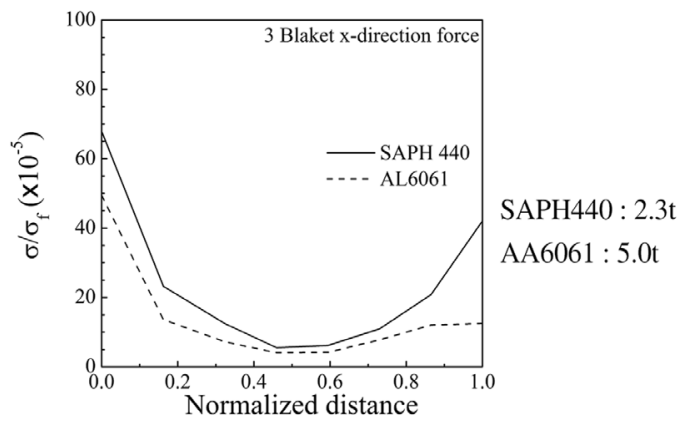

(a) SAPH440:2.3mm, AA6061:5.0mm

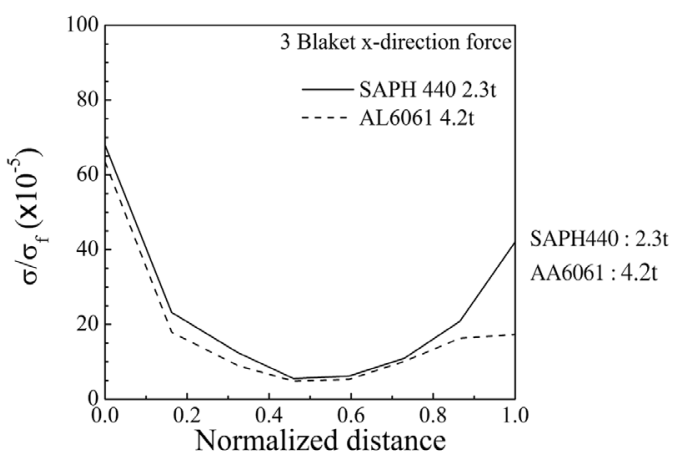

(b) SAPH440:2.3mm, AA6061:4.2mm

Fig. 7 Simulated and optimized results comparison

Table 2 Volume, density and mass comparison between SAPH440 and AA6061 sub-frame

\begin{tabular}{|c|c|c|}
\hline & $\begin{array}{c}\text { SAPH440 } \\
(2.3 \mathrm{~mm} \text { thickness })\end{array}$ & $\begin{array}{c}\text { AA6061 } \\
(4.2 \mathrm{~mm} \text { thickness })\end{array}$ \\
\hline Volume & $2,778,351 \mathrm{~mm}^{3}$ & $5,011,012 \mathrm{~mm}^{3}$ \\
\hline Density & $7.85 \times 10^{-6} \mathrm{~kg} / \mathrm{mm}^{3}$ & $2.75 \times 10^{-6} \mathrm{~kg} / \mathrm{mm}^{3}$ \\
\hline Mass & $21.8 \mathrm{~kg}$ & $13.8 \mathrm{~kg}$ \\
\hline
\end{tabular}

를 도입한 정적해석을 통한 동적특성 최적화 방법 을 이용하면 최적의 두께를 찾아내는데 상당히 간 단하고 유용한 방법임을 알 수 있었다.

\section{후 기}

본 논문은 중소기업청에서 지원하는 2011 년도 산 학연공동기술개발사업(No. 00046571-3)의 연구수 행으로 인한 결과물임을 밝힙니다.

\section{References}

1) S. J. Lee, J. S. Park and D. H. Goo, "The Development of Material Technology Applied 
to Bumper Beam," Transactions of KSAE, Vol.10, No.4, pp.206-215, 2002.

2) J. W. Lee and K. A. Youn, "Hood and Bumper Structure Design Methodology for Pedestrian Regulation," Transactions of KSAE, Vol.13, No.3, pp.162-170, 2005.

3) K. J. Kim and S.-T. Won, "Effect of Structural
Variables on Automotive Body Bumper Impact Beam,” Int. J. Automotive Technology, Vol.9, No.6, pp.713-717, 2008.

4) D. H. Shin, K. H. Kim and K. Sohn, "Analysis of Car-pedestrian Collisions Using Scaled Korean Dummy Models," Journal of KSPE, Vol.24, No.5, pp.110-117, 2007. 